\title{
9
}

\section{PLACE-BASED JOURNALISM, AESTHETICS, AND BRANDING}

\author{
David O. Dowling
}

The debut of Bear 71 at the Sundance Film Festival in 2012 established a major milestone in the evolution of interactive cinema. Five years later, the film's reformatting and re-release in 2017 as a virtual reality (VR) experience viewed through headmounted displays (HMDs) signaled the future of immersive journalism (Jardine 2017). In it, the viewer tracks the movement and behavior of a female grizzly bear in Canada's Banff National Park, which provides the setting for this poignant piece revealing the human impact on wildlife. The VR edition enabled the largescale setting of the wilderness to take on the powerful intimacy of an immersive news experience of the sort showcased in Nonny de la Peña's pioneering Hunger in L.A., which also debuted at Sundance in 2012. As with Bear 71, Hunger in L.A. offered a moving human encounter rather than "cold facts and figures", in its case "by taking a small scale drama and turning it into an emotional confrontation with the everyday reality of hunger in one of the richest countries in the world" (van der Haak 2014). Despite being only seven minutes in length, the work left a deep impression on audiences. "Viewers of the piece tried to touch the nonexistent characters and many cried at the conclusion", according to de la Peña (as quoted in van der Haak 2014). Roughly three times the length, Bear 71's 2017 VR edition expanded the template for the virtual news experience into a more distinctly cinematic, longform mode of storytelling, extending the reach of the medium's already considerable empathic powers.

This chapter examines interactive documentary's evolution since 2012, particularly visible in the emergence of VR/360 journalism. 360- degree video (in spherical rather than flat formatting) viewed through the "magic window" on mobile devices or with HMDs in the more fully immersive VR format have propelled documentary journalism to new technological and narrative heights, achievements attained in part through alternative brand economies, industrial logics and marketing strategies. News organizations, researchers, and tech companies have begun to 
explore cost-efficient ways of bringing immersive video to a mainstream audience. As Watson (2017) notes, 360- degree videos have "made [VR] more accessible to consumers" despite not providing "the immersive experience delivered by a high-end (and more expensive) headset". For journalists, the new VR technology presents one of the most potent storytelling tools in all media, one that demands a thorough reconsideration of editing methods, which have radically destabilized ethical principles of production. Out of this early experimental phase an uneven and highly contested set of best practices has begun to take shape, bearing distinct advantages in spatial storytelling, while diminishing the importance of the cut as a vital editorial tool and means of expression. Interactive video's function as placebased journalism is discussed in the following section. Case studies then examine Google's Beyond the Map, Sports Illustrated's Capturing Everest, and the National Film Board of Canada's Bear 71, immersive documentaries that reflect the industrial protocols of their respective production companies and demonstrate corporate synergies converging into promotional media.

\section{VR documentary as place-based journalism}

The latest phase in the evolution of digital journalism has expanded beyond the linear presentation of facts for passive consumption. Now longer-branching narrative formats within expansive virtual environments situate subjects in their social, political, and economic contexts, which are embodied and dramatized through their geographical surroundings. Subjects of such situated documentaries are thus "more contextualized and placed within a broader environment of events, trends, and issues" (Pavlik \& Bridges 2013, 22). The analytic and ethnographic approach scholars call for as a means of producing more accurate journalism (Neveu 2014; Davis 2016) can be realized in interactive documentary.

Unlike the highly distracting interface of conventional online news, digital journalism produced as interactive documentary provides an immersive app-like environment that eliminates distraction from having multiple windows open in addition to banner and pop-up advertising (Hernandez \& Rue 2016, 105). This highly engaging and interactive design functions as a cognitive container, as the viewer's attention remains in the space of the story world and its embedded multimedia elements without being scattered onto the open web via hyperlinks (Dowling 2017, 103). Although interactive documentaries deploy a wide spectrum of diverse digital designs, most create a sense "of embarking on an experience similar to a video game or movie" within a unified and self-contained story world (Hernandez \& Rue 2016, 103).

Interactive documentaries are linked to $\mathrm{VR}$ in important ways that bear on narrative content as well as user understanding. Aston, Gaudenzi, and Rose (2017) note that interactive documentaries, or "i-docs", include a vast array of projects such as "transmedia documentaries, serious games, locative docs, interactive community media, docu-games", as well as nonfictional VR and live performance documentary. Each of these shares innovation in "documenting away from the lineage of 
documentary film" (2). The cases examined in this chapter provide an interactive experience, one featuring a radical diversity of genre conventions across media akin to Wagner's concept of the Gesamtkunstwerk, an artwork synthesizing a variety of different forms (Aston 2017a). Cases examined here hybridize conventions from documentary film to journalistic data visualization and video games, in the process re-mediating reporting and writing associated with older forms of print longform journalism, particularly investigative and profile feature storytelling. By breaking down the "fourth wall", as Aston (2017a) explains, new "forms of audience engagement and participation [go] beyond the 'point and click' interactivity to screenbased work" (224). Of particular interest here is the effect of works that create "both experiential and readerly ways into documentary content" specifically to challenge the user to "make things feel a little more difficult", as in interactive theater's capacity to "make the hairs stand up on the back of peoples' necks, and to make them feel 'alive"" (Aston 2017a, 224-225). Each case underscores the affirmation that "the future of storytelling is absolutely about placing the audience at the heart of the experience", as Aston (2017a) notes of interactive theater (225).

By navigating data-rich maps, users can experience interactive documentaries on the most intimate level, while also seeing the full expanse of the virtual environment from the seemingly omniscient perspective of 360-degree footage. In this sense, the genre resonates with twenty-first-century place-based literacies and the rise of spatial journalism (Schmitz Weiss 2015). According to Murray (2011), the affordances of digital media are procedural (a set of rules), participatory (inviting action and manipulation of the virtual environment), encyclopedic (the presence of large amounts of data presented in various forms), and spatial (that allows for navigation throughout an information repository and/or virtual environment) (as cited in Aston 2017b). Immersive media - particularly the interactive documentary and multimedia feature - have evolved in such a way as to bring a spatial orientation to the other three major affordances of digital media. Indeed, the spatial dimension of interactive documentary storytelling, as this chapter demonstrates, subsumes procedural, participatory, and encyclopedic affordances. Prior to the emergence of immersive storytelling such as 360- degree video and VR, each of these four affordances was more evenly represented in digital publications, precisely because they lacked the capacity to represent three-dimensional space with such fidelity to the real world, and to plunge the viewer into it so deeply (Aston 2017b).

Interactive documentary encourages a process that in effect "engages a citizenry increasingly disengaged from traditional news" (Pavlik \& Bridges 2013). New media's potential for increased user engagement is particularly evident in 360degree video, which intensifies immediacy through fictional techniques used to capture nonfictional lived events and subjects rather than escapist fantasies (Atkins, McLean, \& Canter 2017). In VR stories viewed through HMDs, imagery plays a crucial role in the effects of narrative transportation (Green \& Brock 2002). There are significant differences, however, between the effects of VR stories, 360-degree video (without HMD), and text on presence, memory, credibility, empathy, and sharing (Sundar et al. 2017). 
This new medium builds on the longstanding principle of nonfiction film as "the art of re-presentation" responsive to "immediate moments" and therefore "rooted in a cultural context that should be studied" (Barsam 1979, 583). Like its pre-digital forbears, the interactive documentary "is usually filmed without sets, costumes, written dialogue, or created sound effects", with the ostensible aim of recreating the sense of "being there" with as much veracity as the situation allows (Barsam 1979, 583). Just as nonfiction film evolved toward increasingly immersive forms in the late 1960s and early 1970s, interactive documentaries have begun expanding toward longer templates, as seen in Capturing Everest.

Prior to HMD and 360 VR technology associated with spherical film, the narrative complexity and emotional import of documentary shot in traditional flat formats steadily increased from the late 1960s to the early 2000s (Bondebjerg 2014). Documentarians have experimented with surreal representations of psychological interiority as in the Japanese film The Man Who Skied Down Everest (1975 Academy Award Winner), dramatic character-based multi-plot narratives as in the critically acclaimed Hoop Dreams (1994), and scientific data visualization as in Al Gore's $A n$ Inconvenient Truth (2006 Academy Award Winner). In such cases, "emotional layers in documentaries appear through narrative structures, through character identification, and through audio-visual effects", techniques also used in fiction films. "But they are also directly connected to content and themes with links to real life" in documentary films, and crucially, "to our decisions to act directly or indirectly when confronted with social problems" (Bondebjerg 2014, 21).

\section{Branching narrative and the Google brand: "beyond the map"}

Google has drawn recognition as an industry leader in mobile digital mapping. To appeal to the coveted mobile audience, $90 \%$ of whom are constantly using location-based services (Anderson 2016), the company has differentiated its maps from the competition by emphasizing place in comparison to more navigationoriented products such as Apple's AR Flyover for iOS 11. Google's augmentation of map locations has advanced beyond visitor reviews and popular times to include contextualizing images and material designed to encourage deeper exploration of communities and cultures. Immersive geographic storytelling is not an end in itself, but a means of inspiring the user to move beyond the map and into the world.

Until recently, the favelas of Brazil's Rio de Janeiro existed outside the reach of online cartographers. Beyond the Map fulfills Google's presumed social mission to bridge the digital divide by mapping this uncharted terrain, and thus give presence and significance to the favelas, most of which were unmapped on Google Maps at the time. The highly sharable series was designed precisely to leverage 2016 Olympic coverage of Rio undertaken by all major media outlets of the world, given the magnitude of the event. This local color of the host city was told through branching or ergotic narrative, as Hernandez and Rue (2016) describe film that allows the viewer to choose their own path through the story (103). Those paths follow several denizens of the favelas. In all cases the narrative avoids soliciting the 
subjects as objects of sentimentality, but instead humanizes them through authentic moving portraits.

A unifying motif connecting each of the figures profiled in Beyond the Map is digital technology, which for one aspiring performance artist takes the form of a video game dance simulator essential to his professional development. Another profile delves into the story of a young woman who seeks a career in computer science, a story directly linked to Google's brand and its theme of bridging the digital divide. A third segment profiles a middle-aged entrepreneur of many stripes who had run a business launching hot air balloons in celebration of prison releases, spectacular shows of freedom financed by family and friends of the released inmate. Google mapping technology in his case improved his business ventures by making him more visible to customers, especially in support of his most recent company specializing in surfing and wind-surfing lessons. Aspiration is a common element connecting their stories, and Google's digital technology plays a central role in each.

According to the film's promotional and branding logics, digital mapping technology is vital to the individual and collective welfare of Brazil's and, by extension, the world's most impoverished populations. Navigation, for example, is crucial to the travel of the young dancer to the academy, and to the entrepreneur in attracting customers through a visible web presence. The film itself, produced in a spherical format, embodies this vision of liberation through technology, as VR/360 and drone cameras joined the cast of characters. Interactive 360-degree shots taken on a motorcycle speeding through the favelas are not mere displays of technological prowess, but help drive the narration of its cartographic theme.

Digital cartography is thus a process of cultural geography, according to the thematic import of Beyond the Map.The work's spatial conception of subjects and styles strongly suggests the formation, however embryonic, of interactive documentary's first genre convention of emphasizing people and place. This spatial orientation reflects "emplacement", defined by Aston (2017) as "the creation, manipulation and sharing of meaning through engaged interaction, bringing our bodies and minds into direct interplay with the wider environment" (233). The viewer never encounters a conventional map; space is represented through spherical filmed footage (as in Google Earth or Satellite) for immersion in the lived ecosystem of the favela communities. This controlling metaphor of cartography - as organizing principle for the film's subject, branding strategies, and user experience - is a selfreflexive iteration of the "third meaning" Barthes $(1977,52)$ describes in film, one that lies just beyond denotation and connotation. The "excess", which constitutes "elements that escape unifying impulses", in this case actually serves the film's unifying principle (as quoted in Bordwell 1985, 53). While the viewer can savor random color, shapes, and sounds on screen not immediately linked to the figure being profiled, such details point to Google's uncanny capacity to evoke a place, and thus support the film's unifying principle of digital technology's role in the cultural geography of developing communities. The third meaning of Beyond the Map is thus industrially and culturally instantiated in the story. 
Interactive documentary editing plays into the viewer's innate desire to assemble a story of the content. According to Sergei Eisenstein, the staging of action is a representational act, "a pattern which the perceivers of narratives create through assumptions and inference". The details behind that pattern, David Bordwell (1985) explains, constitute the data with which "the viewer builds the fabula on the basis of prototype schemata (identifiable types of personas, actions, locales, etc.), template schemata (principally the 'canonic' story), and procedural schemata (a search for appropriate motivations and relations of causality, time and space)", all processes that are intersubjective (49). The interactive documentary has reconfigured the gestural, connotative quality of film by enabling thorough and autonomous exploration of the range of vision of any given shot. What brings unifying meaning to interactive documentary now lies as much in "what is materially present on the screen or soundtrack" as in what is implied beyond it (Bordwell 1985, 49). VR/ 360 technology enables viewers to connect eye-line matches themselves in what is essentially a cut-free experience on the level of the scene.

A major departure from traditional film in interactive documentary lies in the sequencing of events. The viewer of Beyond the Map, for example, is invited to explore the narrative profiles of the figures featured in the film in any order they wish, beginning atop a hill above the sprawling narrow streets of the favelas. In the presence of the narrator the viewer can choose their path in this virtual world as in a video game, thus becoming the architect of their own string of experiences. Useful in understanding the aesthetic and narrative structure of this effect is Roman Jakobson's concept of stylistic composition via paradigmatic groupings based on "the principle of equivalence from the axis of selection to the axis of combination" (quoted in Bordwell 1985, 277). The profile features, for example, are similarly produced in terms of shots, pacing, and duration, each rearranging documentary narration into "paradigmatic groups basic to its construction" (Bordwell 1985, 277). Beyond the Map offers a typology of aspiration as a deep dive into the lives of Rio's inhabitants, told through the immersion of the viewer. The viewer can shift between each profile at will, yet within a virtual environment emphasizing similarities of paradigmatic categories of race, social class, connectivity, privilege, and, ultimately, technology's role in each. (That technological role, of course, bears the Google brand.) As Bordwell describes of film narrative, "any sequence of units phonological, syntactic, semantic - strives to build an equality with the others, creating designs" within the larger work (quoted in Bordwell 1985, 277).

\section{Re-branding Sports Illustrated's longform legacy for the digital age: Capturing Everest}

Just as Google sought uncharted territory in Rio to stake its claim in the new media ecosystem of immersive online storytelling, Sports Illustrated set its sights on the iconic summit of Mount Everest. Capitalizing on spatial journalism's unique appeal to audiences' place-based knowledge (Schmitz Weiss 2015), SI's Capturing Everest reprises the cartographic theme common to immersive media. Profile 
feature storytelling augments the significance of the main narrative covering the dramatic journey to the summit. Brent Bishop serves as veteran guide and son of Barry Bishop, a member of the first American team to reach Everest's summit in 1963. He is joined by Lisa Thompson, breast cancer survivor, and Jeff Glasbrenner, who lost his right leg just below the knee at the age of 12 in a farming accident. Glasbrenner became the first amputee to reach the top of Everest on an expedition that also made media history as the first-ever bottom-to-top ascent of Everest filmed spherically in 360- degree.

Capturing Everest distinguished itself for its length and format consisting of four eight-minute episodes, significantly extending the standard 3-5 minutes for VR. The film functions differently on a narrative level from the highly interactive, datadriven Bear 71. Rather than presenting a map challenging users to decide where to enter the environment, Capturing Everest unfolds in the manner of an on-demand TV docuseries. The sense of immersion is immediate, as the user is treated to an experience previously only available in IMAX theaters. Episode 1 opens during a training session in preparation for Everest. On the high cliff wall, surround footage is at its most compelling. Any distinction between action in front of and behind the camera vanishes in contiguous angles that all contribute vital material to the mise-en-scène. The shot effectively places the viewer on the wall with the climbers, thus breaking down the arbitrary divisions between directed/non-directed action. Non-diegetic narration allows the visuals to dominate. The interactivity here lies not in selecting data caches and scanning maps to navigate the virtual environment as in Bear 71, but in the seemingly omniscient power to scan all angles of every shot. Like Emerson's transparent eyeball in the forest, the user sees all but is nothing, disembodied, and emptied of self precisely to achieve a visceral nearness to nature and humanity.

Cliff-hanger endings, recap openings, and an icon in the upper right of the screen indicating progress toward completion all draw on on-demand television series conventions for the digital design of Capturing Everest. Each episode, however, is packaged to stand alone as an autonomous piece in order to increase spreadability on social media. The film's transmediation extends to SI's print magazine, where readers can use their mobile device to scan the AR box on the cover featuring Glasbrenner. Although HMDs provide the optimal experience, panning or simply swiping a finger on the screen in any direction allows views of the surrounding field of vision. Pictured in action on the mountain, Glasbrenner's prosthesis is prominently displayed on this SI cover.

Rather than relying on voice-of-God narration often used in traditional documentaries, extra-diegetic narrative is supplied through the commentary of the three subjects. The lack of omniscient audio narration allows for a more cinematic viewing experience, precisely because the film instead focuses on "strong central characters doing something filmable directly related to their story", which is the expedition itself, rather than shots of them describing a past accomplishment (Tu 2015, 74). Real-time live events are the staple of televisual sports journalism. To maintain that feel, no SI reporters and production crew appear in the main 
film's audio or visual content. Journalistic control is evident in the explanatory text superimposed on the screen, which is strategically positioned at intervals around the perimeter (rather than clustered in one spot) to encourage exploration of the full panorama. Between action and climbing sequences, characters thus narrate their own stories - providing the color commentary, as it were - through responses to interview questions left off the soundtrack.

SI self-consciously highlighted its legacy in longform journalism, which it had done in its first digital features for its "Going Deep" department established in 2012 just after the publication of Snow Fall (Dowling \& Vogan 2015). To promote Capturing Everest, SI emphasized its brand as legacy longform through Bishop's father's 1963 achievement as a member of the first American team to summit the famous peak. But one decade earlier, SI published the most thorough coverage in the news media at the time on the 1953 first-ever ascent by Sir Edmond Hillary. As with Google's brand-building through digital cartography and ground-breaking exploration by which geographical terrain becomes a trope for technological advancement, SI invoked the space race of the mid-twentieth century as technology and exploration converged "long before the moon landing" when "mankind made its first terrestrial leap" (Stone 2017).

\section{Emerging editorial norms and the 2017 VR edition of Bear 71}

Traditional editorial techniques less reliant on the cut to establish continuity are far more compelling when deployed in 360- degree. The long tracking shot and pan, for example, have become staples of the new medium because it allows the viewer to experience travel and motion with a full range of vision. Hence travel, distance, and movement remain core components of the spatially oriented narratives that have come to define the genre, as seen in Beyond the Map and Capturing Everest. Interestingly, since it is already built into every shot, 360- degree automates panning by in effect placing the camera in the hands of the viewer. 360- degree is ideally suited to journalistic documentary's dedication to verisimilitude by virtue of its reliance on storytelling through spatial narrative emphasizing mise-en-scène rather than through cuts emphasizing time. "The cut is more manipulative" because it "interrupts and remodels reality". By contrast, "the pan is the more realistic [...] since it preserves the integrity of space" (Monaco 1981, 143-144). Andre Bazin observed connections between realism and mise-en-scène, and impressionism and montage, a point useful in explaining 360- degree's predilection toward nonfiction storytelling. What "montage simply did in time is what mise-en-scène does in space", as Jean-Luc Godard noted (cited in Monaco 1981, 145). Journalistic documentary in this sense shares the spatial storytelling staple of mise-en-scène with realistic fiction films. With its space-driven narrative more thickly layered with more mise-en-scène than ever, spherical 360- degree technology uses movement - both the filmmaker's and the viewer's - through the virtual environment to dictate tempo.

Despite the loss of quick cutting and montage as engines driving visual storytelling, producers of VR journalism can maintain narrative control in graphic and 
video overlays as well as direction of subjects before the camera. The technology may be highly automated, but it does not establish the course of the narrative journey nor plot the thematic interconnections between its branches and detours users may choose to pursue. "Audiences will be able to choose different story paths as they freely explore the virtual space", a process akin to open-world gaming, only in a nonfictional context of a " choose your own adventure' version of journalism”, according to a 2017 Associated Press study (Marconi \& Nakagawa 2017).

The viewer of Bear 71 is similarly immersed in a potentially overwhelming amount of data, yet non-diegetic narration maintains focus for the spatial storytelling preferences and place-based knowledge of today's online audience (Schmitz Weiss 2015). Beginning with moving footage of the capture, radio tagging, and release of a three-year-old female grizzly bear in Banff National Park, the piece then releases the viewer to explore the behaviors and travels of the animal - along with some wandering humans mounted with audio and video recording devices through surveillance clips taken by cameras rigged throughout the wilderness. The viewer can navigate the terrain autonomously, as non-linear serendipitous exploration is balanced by Mia Kirschner's narrative voiceover from the perspective of Bear 71, tethering attention to the arc of story that follows the bear's life for the next five years until the dramatic closing scene. While audio maintains narrative trajectory, open-world design encourages autonomous exploration through hundreds of thousands of pictures, clips, and images captured by motion-detector webcams revealing how other tagged animals and humans encroach on the bear's territory and affect her life. In the process of blurring the lines between "story structure, database information, surveillance, and the complex interrelationship between humans and animals", the piece relies on an intense place-based interactive experience (Hernandez \& Rue 2016, 145).

A telling sign of the tech industry's centrality to the evolution of the interactive documentary appeared in Bear 71's 2017 re-release, five years after its original debut, as a virtual reality work designed for viewing with Google Daydream and the more affordable Google Cardboard, headsets designed for use with smartphones. Neither Google, nor any other brand, tech or otherwise, had a stake in the original 2012 production of Bear 71, initially a public media project via the Canadian National Film Board (NFB) and the Canadian National Park system. This corporate partnership arguably may not undermine the conservation message, as the technology of Google Daydream enhances the immersive effect of the medium, and thus its power to move viewers to action (Aitken 2013; Perse \& Lambe 2016) on behalf of wildlife protection.

A key factor distinguishing Bear 71's process of production from those of interactive documentaries by Google and Sports Illustrated lies in its partnerships with both the National Film Board of Canada, for digital architecture and construction, and the Canadian National Park system, for its raw data. Indeed, the piece demanded no independent development of data-gathering devices, methods, or even immersive reportage in a remote location. Instead, a vast untapped data cache of thousands of hours of wildlife footage taken by motion-activated cameras for surveillance 
of Banff National Park was repurposed as the raw material for place-based journalism. Rose (2017) identifies such collaboration as "co-creation", an arrangement that draws subjects, and those close to them, into the process of production, one that enables an activist agenda aiming beyond representation toward social change (51). Leanne Allison originally proposed the project as a traditional documentary to the NFB, who suggested instead an interactive format. The project made novel use of already available technology and resources for the purpose of interactive spatial journalism (Schmitz Weiss 2015). Wired with cameras for conservation and law enforcement purposes, the thoroughly documented Canadian wilderness of Banff was repurposed as an ideal journalistic digital archive. In this sense, the film is the product not of corporate partnerships or branding strategies, but of new video surveillance technology funded by Canadian taxpayers. The automated recordings brought a windfall of data simplifying the information-gathering portion of the reporting process. Thus the film's conservation message traces back to that of the publicly funded data-gathering of Banff National Park, which in turn was shaped into the interactive narrative by the NFB, yet another nonprofit entity charged with serving the public interest rather than marketing its brand.

Unlike the production process for traditional documentary dedicated to shooting extensive original footage and culling a fraction of it for the final cut, the most labor-intensive and time-consuming aspect of Bear 71 was in curating the park's endless low-resolution images and footage. Since Allison shot none of the wildlife footage herself, her task was essentially editorial, yet in ways totally distinct from conventional documentary production, which would have left thousands of hours of footage on the cutting-room floor. The digital archive of Bear 71 lends itself well to VR, as outdoor settings continue to set the standard for interactive web documentaries. The personal connection with subjects in the film, which builds on documentary cinema's increasing use of emotional appeals and literary techniques (Bondebjerg 2014; Parisi \& Holcornb 1994), is enhanced byVR.

\section{Conclusion}

Capturing Everest capitalized on the empathic power of the form when it became the first feature-length film shot in VR released on the internet. The compassion for the climbers, whom the viewer joins in the ascent of the world's most iconic mountain, intensifies in proportion to the film's immersive quality much in the manner of Google's Beyond the Map. Google's partnership in the re-release of Bear 71 by virtue of enabling viewing through Google Daydream and Google Cardboard carries important implications for the role of large tech corporations in the evolution of interactive documentary. News organizations have played a key role in the development of the genre, infusing it with journalistic research, reporting, and writing that remediates print narrative longform genres such as profile, historical, investigative, embedded, and trend feature stories. The interactive documentary thrives on industrial shifts that have given rise to partnerships tracing 
back to Samsung's underwriting of The New York Times' 360- degree experimentation that spawned NYTVR.

Tension in merging journalism and documentary tends to center on filmmakers' reluctance to be shackled by the expectation of reportorial objectivity. In speaking about working with The New York Times on the production of A Short History of the High Rise, for example, NFB producer Gerry Flahive noted that "Journalism is not a term we ever used at NFB in regards to our documentary work. It implies that a point of view is a bad thing, when for documentary filmmakers it is central to the creative act" (Uricchio et al. 2015, 79). Certainly daily breaking news producers can be characterized as resisting point of view and subjectivity.Yet a long and rich tradition of literary journalism featuring the reporter as narrator and/or key character shaping the story is evident in the 1960s New Journalism movement spearheaded by Tom Wolfe. Without eschewing traditional journalism's truth-telling covenants, interactive documentaries also embrace point of view as central to the creative act. The pursuit of rigorous reporting according to the journalistic principle of verification is indeed consonant with the truth claim at the core of documentary filmmaking.

Journalism and documentary combine in cinematic VR for powerfully affective narrative emphasizing felt detail and intimacy with subjects through a heightened sense of embodied presence in a specific place. The centrality of point of view in interactive documentary is evident in the form's genetic blueprint, which traces back to MIT's OpenDocLab that inspired The New York Times' 2012 launch of OpDocs, the first video opinion documentary as a news form. The interactive longform documentary similarly foregrounds the point of view of its creators, yet moves beyond unsupported editorializing into narrative buttressed with rigorous research and reporting, as evident in Beyond the Map, Sports Illustrated's Capturing Everest, and the National Film Board of Canada's Bear 71. Documentary's long dedication to the truth claim as its source of rhetorical power is indeed well suited to journalism's foundational principles of accuracy and verification.VR and media hybridity allows for more fluid definitions of documentary that embraces journalism, a category whose literary forebears align it with, rather than against, "openly rhetorical filmmaking" (Corner 2008, 23). Technological innovations toward increasingly immersive formats now enable documentaries to function both as a subset of journalism and a form as personal as fiction filmmaking that bears the stamp of those who made them, producers ranging from tech companies and legacy media to university labs and national film boards (Bruzzi 2006).

\section{References}

Aitken, Ian. 2013. Form and Reform: John Grierson and the Documentary Film Movement. New York: Routledge.

Anderson, M. 2016. "More Americans Using Smartphones for Getting Directions, Streaming TV.' Pew Research Center, 29 January. www.pewresearch.org/fact-tank/2016/01/29/ us-smartphone-use/ [Accessed 15 March 2020]. 
Aston, Judith. 2017a. "Interactive Documentary and Live Performance: From Embodied to Emplaced Interaction.” In: Judith Aston, Sandra Gaudenzi, \& Mandy Rose (eds), i-Docs: The Evolving Practices of Interactive Documentaries. London: Wallflower Press, pp. 222-231.

Aston, Judith. 2017b. "Interactive Documentary: What Does it Mean and Why Does it Matter?” i-Docs. http://i-docs.org/2016/03/27/interactive-documentary-what-does-itmean-and-why-does-it-matter/ [Accessed 13 October 2019].

Aston, Judith, Sandra Gaudenzi, \& Mandy Rose. 2017. “Introduction.” In: Judith Aston, Sandra Gaudenzi, \& Mandy Rose (eds), i-Docs: The Evolving Practices of Interactive Documentaries. London: Wallflower Press, pp. 1-3.

Atkins, A., D. McLean, \& W. Canter, 2017. "Narrative Transportation, News, 360 Video and Virtual Reality." Poster presented at the American Educators of Journalism and Mass Communication (AEJMC) Conference, Chicago, IL, 6-10 August.

Barsam, Richard Meran. 1979. "Nonfiction Film: The Realist Impulse.” In: Gerald Mast \& Marshall Cohen (eds), Film Theory and Criticism: Introductory Readings. New York: Oxford University Press, pp. 580-593.

Barthes, Roland. 1977. Image, Music, Text. Trans. S. Heath. New York: Hill and Wang.

Bondebjerg, I. 2014. "Documentary and Cognitive Theory: Narrative, Emotion, and Memory." Media and Communication 2(1): 13-22.

Bordwell, D. 1985. Narration in the Fiction Film. Madison, WI: University of Wisconsin Press. Bruzzi, Stella. 2006. New Documentary. 2nd ed. New York: Routledge.

Corner, John. 2008. "Documentary Studies: Dimensions of Transition and Continuity." In: Thomas Austin \& Wilma de Jong (eds), Rethinking Documentary: New Perspectives, New Practices. Berkshire, UK: Open University Press, pp. 13-28.

Davis, S. 2016. "Slowing Down Media Coverage on the US-Mexico Border: News as Sociological Critique in Borderland." Digital Journalism 4(4): 462-477.

Dowling, D. 2017. "Toward a New Aesthetic of Digital Literary Journalism: Charting the Fierce Evolution of the "Supreme Nonfiction." Literary Journalism Studies 9(1): 100-116.

Dowling, D. \& T.Vogan. 2015. "Can we 'Snowfall'This? Digital Longform and the Race for the Tablet Market. Digital Journalism 3(2): 209-224.

Eisenstein, Sergei. 2010. “Towards a Theory of Montage.”. In: Michael A. Glenny \& Richard Taylor (eds), trans. Michael Glenny), Sergei Eisenstein, Selected Works 2. New York: I.B. Tauris.

Green, Melanie C. \& Timothy C. Brock. 2002. “In the Mind's Eye: Transportation-Imagery Model of Narrative Persuasion.” In: Melanie C. Green, Jeffrey J. Strange, \& Timothy C. Brock (eds), Narrative Impact: Social and Cognitive Foundations. Mahwah, NJ: Lawrence Erlbaum, pp. 161-176.

Hernandez, Richard Kosi \& Jeremy Rue. 2016. Principles of Multimedia Journalism: Packaging Digital News. New York: Routledge.

Jardine, A. 2017. "Award-Winning Interactive Film 'Bear 71' Gets a Virtual Reality Makeover." AdAge, 1 March. https://adage.com/creativity/work/bear-71-vr-version/ 51125 [Accessed 15 March 2020].

Marconi, F. \& T. Nakagawa. 2017. “'Choose Your Own Adventure’: VR Journalism Gives Audience Control." Columbia Journalism Review, 3 October. www.cjr.org/tow_center/ virtual-reality-study-engagement.php [Accessed 15 March 2020].

Monaco, James. 1981. How to Read a Film: The Art, Technology, Language, History, and Theory of Film and Media. New York: Oxford. 
Murray, Janet H. 2011. Inventing the Medium: Principles of Interactive Design as a Cultural Practice. Boston: MIT Press.

Neveu, E. 2014. "Revisiting Narrative Journalism as One of the Futures of Journalism." Journalism Studies 15(5): 533-542.

Parisi, P. \& B. Holcornb. 1994. "Symbolizing place: Journalistic narratives of the city." Urban Geography 15(4): 376-394.

Pavlik, John V. \& Frank Bridges. 2013. "The Emergence of Augmented Reality (AR) as a Storytelling Medium in Journalism.” Journalism \& Communication Monographs 15(1): 4-59.

Perse, Elizabeth \& Jennifer Lambe. 2016. Media Effects and Society. New York: Routledge.

Rose, Mandy. 2017. "Not Media About, but Media With: Co-creation for Activism." In: Judith Aston, Sandra Gaudenzi, \& Mandy Rose (eds), i-Docs: The Evolving Practices of Interactive Documentaries. London: Wallflower Press, pp. 49-65.

Schmitz Weiss, A. 2015. "Place-based Knowledge in the Twenty-First Century: The Creation of Spatial Journalism.” Digital Journalism 3(1): 116-131.

Stone, C. 2017. "Editor's Note: Experience a Climb to the Top of the World with SI's Capturing Everest." Sports Illustrated, May. www.si.com/more-sports/2017/capturingeverest-editors-note-sports-illustrated-virtual-reality [Accessed 15 March 2020].

Sundar, S.S., J. Kang, \& D. Oprean. 2017. "Being There in the Midst of the Story: How immersive Journalism Affects Our Perceptions and Cognitions." Cyberpsychology, Behavior, and Social Networking 20(11): 672-682.

Tu, Duy Linh. 2015. Feature and Narrative Storytelling for Multimedia Journalists. New York: Focal Press.

Uricchio, William, S. Wolozin, L. Bui, et al. 2015. Mapping the Intersection of Two Cultures: Interactive Documentary and Digital Journalism. Boston: MIT Open Documentary Lab, MacArthur Foundation.

van der Haak, B. 2014. "Hunger in L.A.” Multiple Journalism. www.multiplejournalism.org/ case/hunger-in-la [Accessed 15 March 2020].

Watson, Zillah. 2017. VR for News: The New Reality? Digital News Project. Oxford, UK: Reuters Institute for the Study of Journalism, University of Oxford. https:// reutersinstitute.politics.ox.ac.uk/our-research/vr-news-new-reality [Accessed 15 March 2020]. 